\title{
Towards effective and sustainable global academic partnerships through a maturity model informed by the capability approach
}

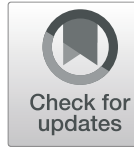

\author{
Abebaw Fekadu ${ }^{1,2,3^{*}}$ (D), Esubalew Assefa ${ }^{1,4}$, Abraham Tesfaye ${ }^{1}$, Charlotte Hanlon ${ }^{1,3,5}$, Belete Adefris ${ }^{1}$, \\ Tsegahun Manyazewal', Melanie J. Newport ${ }^{2}$ and Gail Davey ${ }^{2,6}$
}

\begin{abstract}
Background: Shortage of skilled workforce is a global concern but represents a critical bottleneck to Africa's development. While global academic partnerships have the potential to help tackle this development bottleneck, they are criticised for inadequate attention to equity, impact, and sustainability. We propose a new values-driven partnership model for sustainable and equitable global partnerships that achieve impact.

Method: The model was based on the authors' experiences of participation in over 30 partnerships and used insights from the Capability Approach.

Results: We developed an Academic Partnership Maturity Model, with five levels of maturity, extending from precontemplative to mature partnerships. The level of maturity increases depending on the level of freedom, equity, diversity, and agency afforded to the partners. The approach offers a framework for establishing a forward-looking partnership anchored in mutual learning, empowerment, and autonomy.
\end{abstract}

Conclusion: This is a pragmatic model limited by the biases of experiential knowledge. Further development of the concept, including metrics and an evaluation tool kit are needed to assist partners and funders.

Keywords: Academic partnership maturity model, Global partnerships, Sustainable development goals, Capability

\section{Background}

The potential of global partnerships to assist low- and middle-income countries as they strive to address their development challenges is substantial $[1,2]$. This is particularly relevant when building skilled workforce through academic partnerships. While shortage of skilled workforce is a global concern [3], it represents a serious threat to Africa's development $[3,4]$ and impedes Africa's potential to contribute to global welfare. For example, whereas globally, over 1000 researchers are available per million

\footnotetext{
* Correspondence: abebaw.fekadu@aau.edu.et

${ }^{1}$ Centre for Innovative Drug Development and Therapeutic Trials for Africa (CDT-Africa), Addis Ababa University, Addis Ababa, Ethiopia

${ }^{2}$ Global Health \& Infection Department, Brighton and Sussex Medical School, Brighton, UK

Full list of author information is available at the end of the article
}

population, only 92 are available in Africa [5]. In the context of population growth, climate change and pandemics, this severe shortfall in expertise can translate into an existential threat for Africa. Global partnerships may be a major path to rectifying this gap. In recognition of its potential role, global partnerships have taken a central role in the global development agenda expressed in the Millennium Development Goals (MDG) and the Sustainable Development Goals (SDG). The last goal (Goal 17) of the SDGs is dedicated to partnership as a means of achieving the SDGs, with at least eight of the 19 targets referring to partnership and capacity building. These targets emphasise cooperation for knowledge sharing, technology transfer and

(c) The Author(s). 2021 Open Access This article is licensed under a Creative Commons Attribution 4.0 International License, which permits use, sharing, adaptation, distribution and reproduction in any medium or format, as long as you give appropriate credit to the original author(s) and the source, provide a link to the Creative Commons licence, and indicate if changes were made. The images or other third party material in this article are included in the article's Creative Commons licence, unless indicated otherwise in a credit line to the material. If material is not included in the article's Creative Commons licence and your intended use is not permitted by statutory regulation or exceeds the permitted use, you will need to obtain permission directly from the copyright holder. To view a copy of this licence, visit http://creativecommons.org/licenses/by/4.0/ The Creative Commons Public Domain Dedication waiver (http://creativecommons.org/publicdomain/zero/1.0/) applies to the data made available in this article, unless otherwise stated in a credit line to the data. 
innovation to support national plans for achieving sustainable development [2].

Alongside the SDGs, the United Nations Industrial Development Organization (UNIDO) has proposed a Programme for Country Partnership (PCP) [6] aimed at "accelerating inclusive and sustainable industrial development". The PCP encourages mobilisation of "partners and resources to achieve larger development impact". A recent World Bank Africa Centres of Excellence initiative, which recognises the lack of skilled manpower in the sciences as a critical development challenge for Africa, employs partnership as a major tool to support African higher education institutions to address this critical challenge [4]. Another important initiative, the Partnership for Applied Science, Engineering, and Technology, is designed to leverage a partnership with countries in Asia and Latin America (Brazil, China, India and the Republic of South Korea) to improve knowledge and expertise in the applied sciences [5].

However, although undoubtedly important, global academic partnerships are complex [7], influenced by relationship dynamics, geopolitical issues and mismanagement. They are often short-term, with an agenda that is not always co-developed. Furthermore, at present, the focus of global partnerships is primarily on addressing system or process challenges rather than on functions that are more likely to lead to autonomy, freedom, and mutual benefit, for example, development of critical technological expertise and infrastructure. Achieving sustainable development through partnership requires longer-term and predictable engagement between partners guided by considerations of mutual growth, maturity and sustainability. The various guidelines and principles put forward to ensure sustainability and equity [8-11] do not offer guidance on how partnerships should be built to last. The main objective of this commentary is to propose a value driven maturity model for academic partnerships informed by the Capability Approach [12, 13]. This model may assist academic relationships to develop strategically with a clear intent for longer-term impactful engagements. We first expand on the rationale for a new model before describing the new partnership model and suggest mechanisms derived from the insights of the Capability Approach to strengthen partnerships.

\section{Why a new model for global academic partnerships?}

There is a clear mismatch between what global academic partnerships can achieve and what they are achieving currently. Geopolitical, institutional and personal factors as well as the often short-term, project driven, and inequitable nature of global academic partnerships $[4,8,14]$ partly explain the mismatch. Achieving sustainable development through partnerships requires planned, long-term, and equitable relationships between partners. Some funding mechanisms incentivise partnership frameworks with potential for equity [15]. While these are important initiatives, sustainable partnerships must emanate from a sense of institutional freedom. Encouraging partnerships through incentives, legislation or simply from a sense of moral duty is unlikely to work effectively or sustainably [16].

Various frameworks have been put forward to assist with establishing and monitoring partnerships. The ESSENCE research framework [8] sets out seven principles that aim to support the "coordination and harmonization of research capacity investment". The framework emphasises implementation principles: understanding of local context, local ownership, capacity assessment, research governance, monitoring and sustainability. The Research Fairness Initiative evaluates the fairness of research and partnerships in terms of working along national priorities and equity [11]. Another important principle is set by the Tropical Health and Education Trust (THET), a healthcare delivery partnership [9]. THET sets out eight hallmarks that includes some value propositions, such as reciprocity and respect. It also includes an assessment tool against the eight hallmarks. The Swiss Commission for Research Partnership with Developing Countries [14] offers a guideline with 11 principles, which focus on the planning, implementation and application of research. It also provides questions to explore the nature of the partnership and translation of research findings into societal benefit. Recognising that most of these "north-south" partnership guidelines were developed from the perspective of "northern' partners perspective, the Canadian Association for Global Health joined up with three "southern" institutions to develop a partnership assessment tool with the objective of developing an agreement on five key elements: sustainability, knowledge production, knowledge translation, capacity development and innovation [10]. The Collaborative Advantage Framework has been developed to maximise the impact of SDG partnerships [17]. The framework describes 10 ways to create additional 'value' and maximise advantage for impact and reduce risk. All in all, these are very important frameworks. However, the criticism that they primarily address the perspectives of 'northern' institutions and funders is not addressed adequately. Several of the frameworks offer a case for attaining the benefits of partnership rather than proposing mechanisms on building and sustaining partnerships. The values proposed in some of the frameworks are also more business driven than 'equity' driven. There is a clear need for a model that suggests a path for establishing a forward-looking partnership anchored in mutual learning, empowerment, autonomy, and freedom. 


\section{Moving towards a mature academic partnership: insights from the capability approach}

The Capability Approach emerged as a critique to the ways in which poverty, development and wellbeing were conceptualised and measured [18]. Rather than focusing on resources or income, it argues for freedoms and opportunities, with a focus on capabilities. Development thus conceptualised is about the expansion of freedom and opportunities to be or to do the things individuals have a reason to value [13].

The Capability Approach can offer insights to partnerships in three main areas. First, as a value framework, it brings attention not to mere access to resources but to the freedoms they provide to achieve things of value. Academic partnerships can improve access to resources, infrastructure and skills. However, mature partnerships should reach beyond resources and offer freedoms to enable partners to convert or appropriate resources towards the improvement of well-being or other dimensions they value.

Second, the Capability Approach places attention on diversity among people and their

circumstances. This implies that their ability to convert resources into capabilities can vary and that evaluations must take context into account [12, 13]. Mature partnerships will require an understanding of the diversity and complexity of circumstances and will explicitly engage with them.

Third, one of the pillars of the Capability Approach is agency and the view of people as change agents $[19,20]$ with focus on the expansion of agency and the need to address imbalances and power asymmetries that influence it. Mature partnerships should consider all partners to be active agents of change. Alignment of values, and other key elements, such as freedom, trust, and strategic investment are foundational for growing sustainable and mutually beneficial partnerships.

\section{An academic partnership maturity model}

Collaboration maturity models describe the progressive steps that lead to productive relationships between partners for the purposes of pulling strengths together and obtaining competitive advantages. In the context of global academic partnerships, the driving principle needs to be values, particularly in the presence of major cultural chasms and power imbalances.

We propose a values-driven and progressive academic partnership maturity model for global partnerships anchored in equity, mutual benefit, growth, and sustainability. This model was developed through reflexive methods, in which the experience of the authors in participating and supporting partnerships was the main input. The authors collectively have developed more than 30 partnerships in the past two decades.
This model proposes five levels/stages of partnership maturity (Fig. 1). Not all partnerships need to go through all the stages or levels.

\section{Level 1: Uninitiated [pre-contemplative]}

Institutions at this level of maturity are not interested in or are not aware of global partnerships. These institutions may be helped to contemplate or consider the benefits of engaging in partnership through sensitisation and advocacy. This level is included to ensure that all institutions stand to benefit from what partnerships offer.

\section{Level 2: Exploring [Contemplative]}

Institutions at this level are interested in the potential of partnerships. They show cultural curiosity and are looking out for or exploring opportunities for partnerships. These institutions may benefit from discussion with institutions with experience as well as organizations that may facilitate partnerships to move to the next stage.

\section{Level 3: Engaged}

At this level, institutions have established relationships, including engagement in education and/or research. The relationship may take a formalised structure such as a Memorandum of Understanding. They have defined what they and their partners may want. However, these relationships are often unidirectional and superficial, and struggle to take root. Ingressive behaviour may dominate. This is a critical stage in the maturity model where partnerships may die because of discouragement and lack of engagement from senior staff. The institutions must take strategic decisions to give their relationship a chance to grow.

\section{Level 4: Committed}

There is clear engagement at senior staff level. Firm agreement frameworks are in place and are implemented. Multiple programmes are part of the partnership. Partners have sincere desire and evidence of commitment to each other and to build capacity. Congressive behaviour dominates. Strategic plans that reflect standard partnership capacity building principles are in place.

\section{Level 5: Mature}

With mature partnerships, formalised relationships beyond individual scientists are in place. Institutional leaders are engaged, and governance and monitoring structures are agreed. The relationship is no longer project specific although multiple projects are common. The relationship is on a sustainable footing. Both parties have confidence in the relationship and benefit from the relationship. There is mutual knowledge and affirmation of culture and deep respect. Joint innovation 


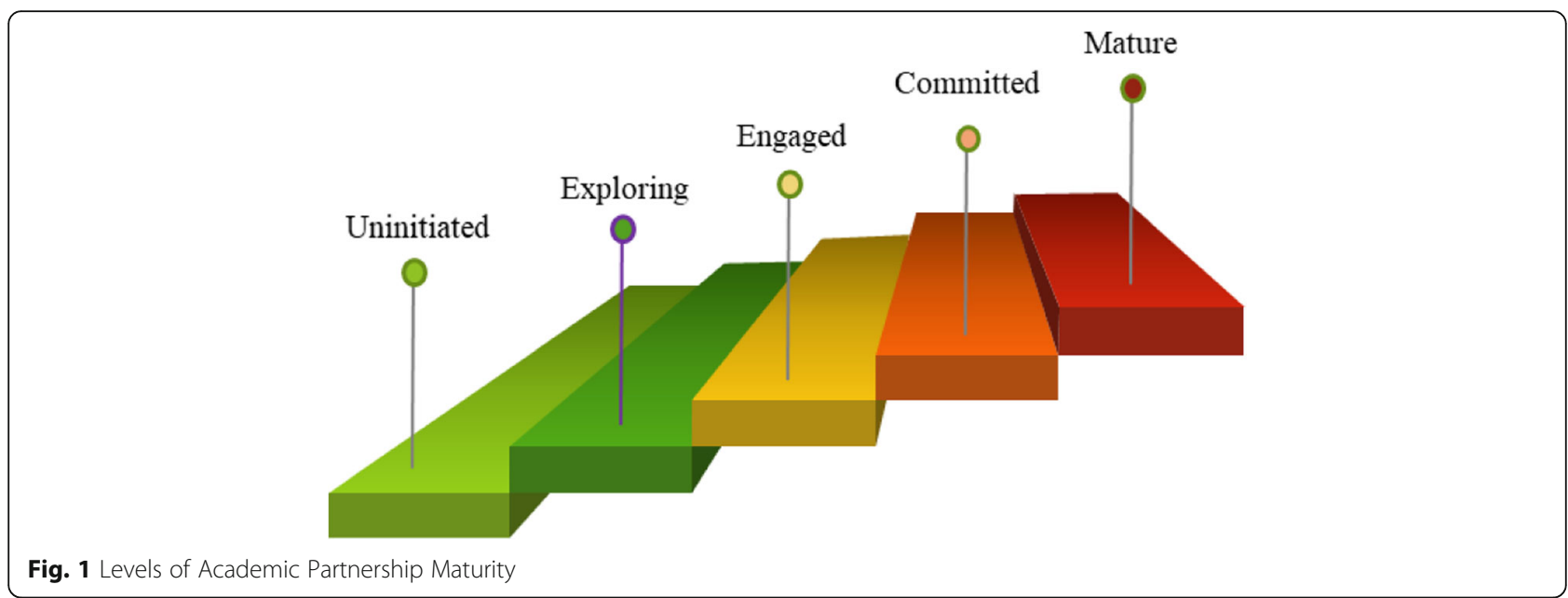

programmes may take place with the potential for sensitive undertakings, such as commercial exploitation. The partners are committed to strategic investments and there maybe joint infrastructure or other joint centres. The partnership enjoys shared values. Regular evaluations of the relationship at senior management level are important to address any emerging trajectories and engage the relationship in exciting new opportunities.

\section{Considerations for strengthening partnerships}

Five elements related to the Capability Approach are considered: Aligned Values, Freedom, Empowerment, Trust, and Strategic Investment (Fig. 2).

\section{Aligned values}

Values that go beyond the usual 'transparency' and 'accountability' are needed. Compassion, generosity, stewardship, equity, innovativeness and being solutions- focused are values that support reciprocity, dependability, mutual growth, and address any challenges in the relationship or task implementation.

\section{Freedom}

Is at the heart of the Capability Approach and is related mainly to the ability to have genuine choice. In relation to partnership, this would be related to the ability to choose to be in the partnership and expansion of freedom and the ability to have agency and autonomy. The freedom to move and enjoy and learn from the partnership should be supported. Freedom forms the basis or the foundation of any academic partnership and the prospect of growth and sustainability.

\section{Empowerment}

Is about enabling partners to grow. It is about creating an enabling space and supplement capability so that the

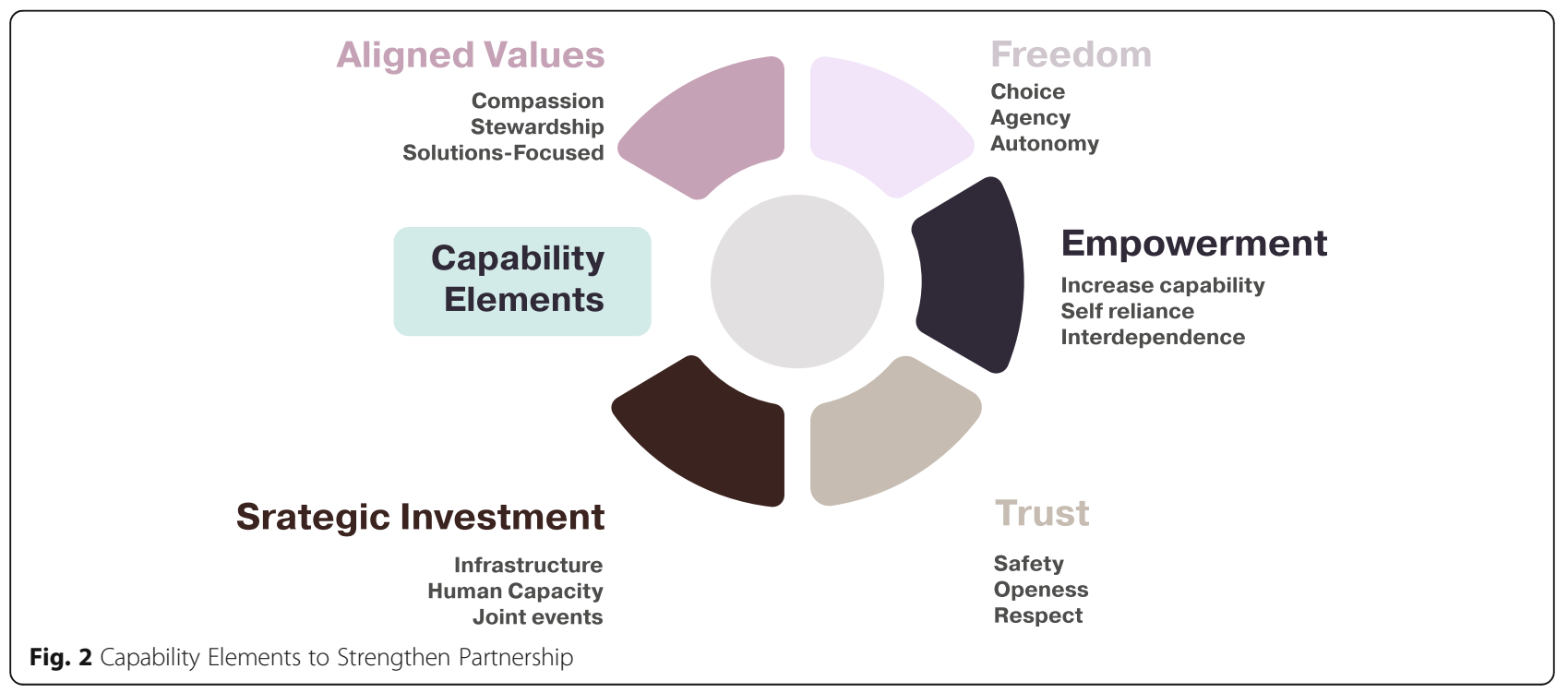


other partner is free to grow, reduce dependence and be self-reliant. This enables partners to contribute more to the partnership.

\section{Trust}

Is related to safety of operations and relations. How much does one feel safe and confident navigating through a relationship environment. It requires sufficient knowledge of the operation environment, openness, respect, and reciprocity. Sense of safety increases confidence and creates a nurturing environment for the relationship to grow.

\section{Strategic investment}

This may be considered part of the empowering exchange in the partnership and related to a broader strategic plan. This should include joint investment for creating joint spaces, Research and Development (R\&D) infrastructure and expertise as well as opportunities for mutual recognition and affirmation. The African region only accounted for $1.6 \%$ of the global investment in R\&D in 2016, with marked disparity within Africa [21]. Such strategic investment is fundamental to ensure equitable partnership. This should include joint investment for creating joint spaces, infrastructure as well as opportunities for mutual recognition and affirmation.

We think that increasing incorporation of these elements will lead to stronger and more impactful relationships. These relationships would not be possible without the funders and institutions that support thriving partnerships. As funders are interested in the bigger and longerterm impact of the invested resources, serious considerations should be given by funders to support these elements and offer some provisions for flexibility in the use of funds without compromising accountability.

\section{The practice aspects of implementing a successful partnership}

We attempt to demonstrate the design and implementation aspects of a successful partnership by offering the relationship between Addis Ababa University, Brighton and Sussex Medical School and King's College London as an example (Boxes 1 and 2). Although there was no deliberate effort, the implementation of this partnership maps well with some aspects of the established practice guidelines, such as the ESSENCE framework [8]. The relationships were established over 15 years and all participants of the partnerships had made a deliberate effort to understand the culture of partner countries and institutions. Decisions around funding allocations, publications and involvement of new partners were made transparently following open discussions. Decisions recognised the relative strengths of each partner. Results, risks, and constraints were reviewed and discussed regularly.
Box 1 Design aspects of a partnership

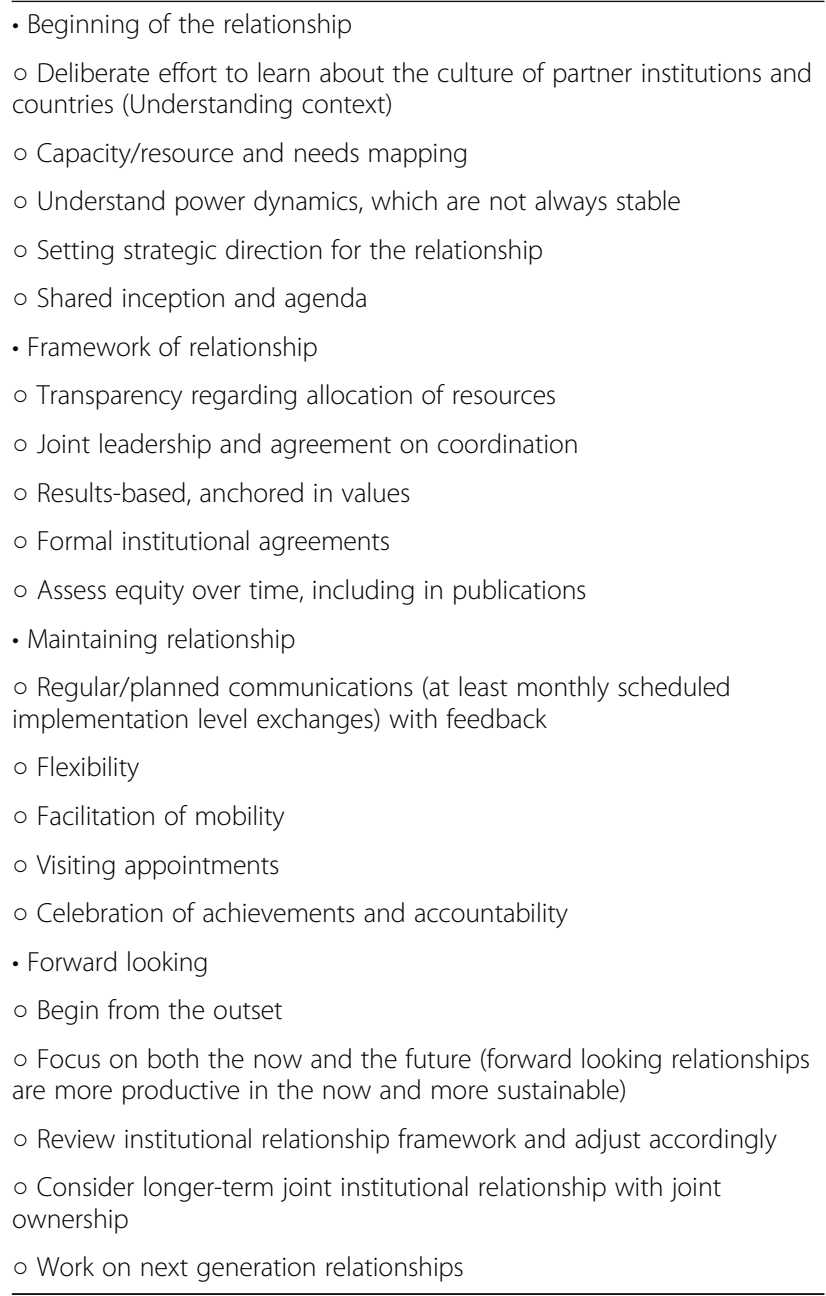

Flexibility was one of the hallmarks of the partnership. This was shown particularly during the COVID-19 pandemic when implementation of activities was drastically affected. The flexibility included rescheduling deliverables, and funding reallocations with the consent of the funder(s). As an example, when students were unable to use the cell culture laboratory in the north institution, the decision was made to establish a cell culture

\section{Box 2 Key equity areas}
- Inception/agenda setting
- Decision making
- Mobility
- Expertise
- Infrastructure
- Publications
- Resource allocation
- Overheads
- Administrative controls 
laboratory in the south institution and implemented. A new programme of post-doctoral fellowship was developed to ensure sustainable capacity building as well as to build foundations for the next generation relationship. Mobility was also supported to enhance knowledge exchange and equity. Partners worked to negotiate with relevant agencies to ensure that mobility of partners was maintained. There is a need to expand infrastructure and scale up the relationship with more departments within institutions to make the relationship more impactful.

It is of note that the model is new, untested, and susceptible to the limitations of experiential knowledge. Further development of the framework with additional metrices and assessment tools is needed. The model also does not consider consortia, which may have larger impact with bigger constraints. The current maturity model may be adapted considering the complexities of a consortium.

\section{Conclusion}

We have presented the Academic Partnership Maturity Model with the hope of encouraging at least some global partnerships to enter relationships with clear intent of longer-term value driven engagement. While we recognise that short term, goal driven collaborations are important, we believe that long term partnerships are crucial to attain lasting impact. Such partnerships are more likely to emerge if they are founded on principles of mutual benefit in which experiences and knowledge are exchanged equitably between the partners. Although not highlighted within the model sufficiently, the sustained underinvestment in research infrastructure in academic institutions, particularly in Africa [22], should be considered a major threat to freedom and equitable partnership for development. As long as funders and nations fail to invest in research infrastructure in low-income countries, the freedom that comes through global partnerships will remain a pipe dream.

\section{Acknowledgements}

None.

\section{Authors' contributions}

AF, EA, MJN, GD: developed the initial idea. AF and EA: drafted the paper. AF, EA, AT, CH, BA, TM, MJN and GD: Critically revised the paper and made significant intellectual contributions. The author(s) read and approved the final manuscript.

\section{Funding}

No funding for this work.

Availability of data and materials

Not applicable.

\section{Declarations}

Ethics approval and consent to participate Not applicable.
Consent for publication

Not applicable.

\section{Competing interests}

None.

\section{Author details}

${ }^{1}$ Centre for Innovative Drug Development and Therapeutic Trials for Africa (CDT-Africa), Addis Ababa University, Addis Ababa, Ethiopia. ${ }^{2}$ Global Health \& Infection Department, Brighton and Sussex Medical School, Brighton, UK. ${ }^{3}$ Department of Psychiatry, WHO Collaborating Centre for Mental Health Research and Capacity-Building, School of Medicine, College of Health Sciences, Addis Ababa University, Addis Ababa, Ethiopia. ${ }^{4}$ Department of Economics, College of Business and Economics, Jimma University, Jimma, Ethiopia. ${ }^{5}$ Health Services and Population Research Department, Centre for Global Mental Health, King's College London, London, UK. 'S School of Public Health, College of Health Sciences, Addis Ababa University, Addis Ababa, Ethiopia.

Received: 8 July 2021 Accepted: 9 November 2021

Published online: 20 November 2021

\section{References}

1. Carnegie Corporation of New York. [Raising the grade [Available from: https://www.carnegie.org/interactives/hera/\#!!/ Accessed 06 Mar 2021 2021.]

2. United Nations. Transforming our world: the 2030 agenda for sustainable development [Available from: https://sustainabledevelopment.un.org/ content/documents/21252030\%20Agenda\%20for\%20Sustainable\%2 ODevelopment\%20web.pdf Accessed 18 Feb 2021 2021.]

3. PwC. [22nd Annual Global CEO Survey 2019 [Available from: https://www. pwc.com/gx/en/ceo-survey/2019/report/pwc-22nd-annual-global-ceosurvey.pdf Accessed 23 Oct 2020.]

4. World Bank: A Regional Solution to Transform Science and Technology Education in Africa. 2016.

5. Office of the Chief Economist for the Africa group, the World Bank group. [Africa's Pulse 2017 [Available from: http://documents1.worldbank.org/cura ted/en/572941507636665377/pdf/120334-REVISED-100p-WB-AfricasPulse-Fa ||2017-vol16-webfinal-english.pdf Accessed 23 Oct 2020 ].

6. United Nations Industrial Development Organization. [Sustainabble industrical development for shared prosperity 2017 [Available from: https:// www.unido.org/sites/default/files/files/2017-11/PCP_24.11.17.pdf Accessed 23 Oct 2020.]

7. Obamba MO, Mwema JK. Symmetry and asymmetry: new contours, paradigms, and politics in African academic partnerships. Higher Education Policy. 2009;22(3):349-71. https://doi.org/10.1057/hep.2009.12.

8. ESSENCE on Health Research: Seven principles for strengthening research capacity in low- and middle-income countries: simple ideas in a complex world: ESSENCE Good practice document series. 2014.

9. Tropical Health and Education Trust (THET). [Principles of Partnership [Available from: https://www.thet.org/principles-of-partnership/ Accessed 3 Oct 2020.]

10. Afsana K, Habte D, Hatfield J, Murphy J, Neufeld V. [Partnership Assessment Toolkit: Candadian Coalition for Global Health Research; 2009 [Available from: https://www.elrha.org/wp-content/uploads/2014/08/PAT_Interactive_ e-1.pdf Accessed 23 Oct 2020.]

11. Council on Health Research for Development (COHRED). Research Fairness Initiative Implementation Guide. [Available from: https://rfi.cohred.org/wpcontent/uploads/2018/04/RFI_SummaryGuide_EN_v2.0_20180315.pdf. (Accessed 3 Oct 2020).

12. Robeyns I. The capability approach: a theoretical survey. J Hum Dev. 2005; 6(1):93-117. https://doi.org/10.1080/146498805200034266.

13. Sen A. Development as freedom. New York: Alfred Knopf; 1999.

14. Swiss Commission for Research Partnerships with Developing Countries (KFPE). [A Guide for Transboundary Research Partnerships: 11 Principles 2018 [Available from: https://naturalsciences.ch/service/publications/9505-a-guidefor-transboundary-research-partnerships-3rd-edition. Accessed 3 Oct 2020].

15. Fekadu A, Oppenheim C, Manyazewal T, Nislow C, Woldeamanuel Y, Hailu $A$, et al. Understanding the key processes of excellence as a prerequisite to establishing academic centres of excellence in Africa. BMC Med Educ. 2021; 21(1):36. https://doi.org/10.1186/s12909-020-02471-0. 
16. Ejere G: Thinking in progress: cooperation under control? The dilemma of partnering with the state. 2006. Available at: https:/thepartneringinitiative. org/wp-content/uploads/2014/08/PartnershipMatters4.pdf. Accessed 18 Feb 2021.

17. Stibbe D, Prescott D. The SDG partnership guidebook: a practical guide to building highimpact multi-stakeholder partnerships for the sustainable development goals: the partnering initiative and UNDESA; 2020.

18. McCoy D, Mwansambo C, Costello A, Khan A. Academic partnerships between rich and poor countries. Lancet. 2008;371(9618):1055-7. https://doi. org/10.1016/50140-6736(08)60466-3.

19. Frediani AA, Boni A, Gasper D. Approaching development projects from a human development and capability perspective. J Human Dev Capabilities. 2014;15(1):1-12. https://doi.org/10.1080/19452829.2013.879014.

20. Crocker DA, Robeyns I. Capability and Agency. In: Morris CW, editor. Amartya Sen Contemporary Philosophy in Focus. Cambridge: Cambridge University Press; 2009. p. 60-90. https://doi.org/10.1017/CBO9780511800511. 005.

21. Simpkin V, Namubiru-Mwaura E, Clarke L, Mossialos E. Investing in health R\&D: where we are, what limits us, and how to make progress in Africa. BMJ Glob Health. 2019;4(2):e001047. https://doi.org/10.1136/bmjgh-2018001047.

22. HEART RCf. [Strengthening Research Institutions in Africa: A Synthesis Report 2019 [Available from: https://assets.publishing.service.gov.uk/media/ 5ef4ac4986650c12a0c778a7/Synthesis_report_Final_revised_v3_clean_.pdf Accessed 20 Oct 2021.]

\section{Publisher's Note}

Springer Nature remains neutral with regard to jurisdictional claims in published maps and institutional affiliations.

Ready to submit your research? Choose BMC and benefit from:

- fast, convenient online submission

- thorough peer review by experienced researchers in your field

- rapid publication on acceptance

- support for research data, including large and complex data types

- gold Open Access which fosters wider collaboration and increased citations

- maximum visibility for your research: over $100 \mathrm{M}$ website views per year

At $\mathrm{BMC}$, research is always in progress.

Learn more biomedcentral.com/submissions 